\title{
CFD Analysis of Heat Transfer and Flow Resistance on Shell Side of the Spiral Elliptical Tube Heat Exchanger
}

\author{
Sheng Yang ${ }^{1, a^{*}}$, Teng $\mathrm{Hu}^{2, \mathrm{~b}}$, Li Zhang ${ }^{3, \mathrm{c}}$ and Ming Zhang ${ }^{4, \mathrm{~d}}$ \\ ${ }^{1,2,4}$ State Nuclear Power Technology Research and Development Center, South Area, Future \\ Science and Technology Park, Chang Ping District, Beijing, 102209, P.R. China \\ ${ }^{3}$ State Key Laboratory of Chemical Engineering, School of Mechanical and Power Engineering, East \\ China University of Science and Technology, Shanghai, 200237, P.R. China \\ ayangsheng@snptc.com.cn, bhuteng@snptc.com.cn, 'Izhang@ecust.edu.cn, \\ dzhangming1@snptc.com.cn
}

Keywords: Spiral elliptical tube; Shell side; heat transfer; flow resistance; CFD

Abstract. Shell side heat transfer and flow resistance characteristics of the spiral elliptical tube heat exchanger and smooth tube heat exchanger with segmental baffle were investigated using CFD method. Basing on this investigation, the appropriate applications of spiral elliptical tube heat exchangers were analyzed. The results showed the spiral elliptical tube has no effect on shell side heat transfer enhancement, however the shell side flow resistance of a spiral elliptical tube exchanger is far less than that of a smooth tube heat exchanger with segmental baffle and the comprehensive performance is much better than the latter. The spiral elliptical tube heat exchanger is more suitable for the cases of large fluid flow rate, high pressure drop, fluid easy scaling and easy to induce bundle vibration on shell side.

\section{Introduction}

Heat exchangers are widely used in many industrial areas, such as petroleum refining, chemical engineering, power plant, and so on. The most commonly used heat exchanger is the conventional shell-and-tube heat exchanger with segmental baffles (HESB) due to its robust geometry construction, easy maintenance and possible upgrade [1]. However, there are several drawbacks of the conventional HESB: large pressure drop on the shell side, high range of dead zones and back flows between two adjacent segmental baffles which lead to an increase of scaling resistance, and the dramatic zigzag flow also causes high risk of vibration failure on the tube bundle. To overcome such shortcomings of the HESB, some novel heat exchangers including the spiral elliptical tube heat exchanger (SETHE) are developed and applied in practice. The SETHE eliminates the baffles entirely by arranging the spiral elliptical tubes to support themselves. The spiral elliptical tube is formed into an elliptical cross section with a superimposed spiral as illustrated in Fig.1 and is left round at two ends for conventional fixing into tube sheet [2]. The geometrical features of a SET include the 360 degree spiral pitch (S), major dimension (A) and minor dimension (B) of the cross section. In the tube bundle, unique SETs are arranged in triangular pattern, and each tube is firmly and frequently supported by adjacent ones at their wider sides, therefore tube fretting and failure due to flow-induced vibration is eliminated. The baffle free design directs the shell side flow to predominantly longitudinal flow, which can reduce the pressure drop associated with segmental baffles. Shell side flow velocity is constant and uniform, so dead spots are eliminated and scaling is reduced.

About the performance of SETHEs, the tube side heat transfer and pressure drop properties have been studied extensively [3, 4]. However, not enough investigation on the shell side performance of a SETHE has been done. In view of this, a CFD analysis about flow and heat transfer on shell side of the SETHE was conducted. Numerical results were presented in details, including the flow field, fluid temperature and pressure drop distributions on shell side. Shell side performance of the SETHE was evaluated and compared with a conventional HESB, and the suitable application occasion of the SETHE was also analyzed. 


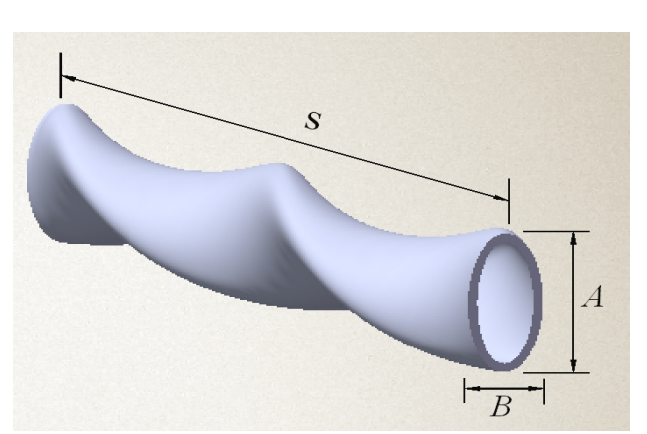

Fig.1 The spiral elliptical tube section

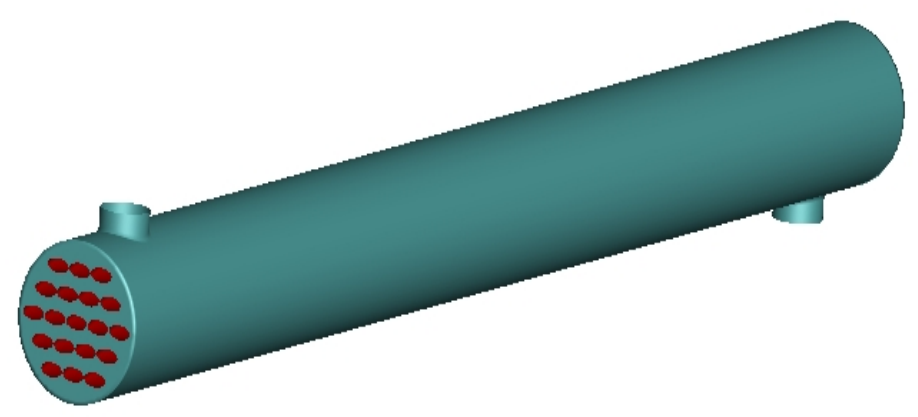

Fig. 2 Three-dimensional model of a SETHE

\section{CFD Modeling Details}

The computational model of a SETHE is established as shown in Fig.2. The structural parameters of the SETHE are listed in Table 1. For comparison, a conventional HESB is also simulated. For turbulent flow modeling, the renormalization group (RNG) k- $\varepsilon$ model[5] is adopted for it can provide improved predictions of near wall flow and flow with high streamline curvature. In the derivation of this model, it is assumed that the flow is fully turbulent, and the effect of molecular viscosity is negligible.

Table 1 Structural parameters of the simulated SETHE model

\begin{tabular}{ll}
\hline Item & Dimensions \\
\hline Shell diameter & $147[\mathrm{~mm}]$ \\
Major axis of the SET & $25[\mathrm{~mm}]$ \\
Spiral pitch of the SET & $100[\mathrm{~mm}]$ \\
Tube bundle geometry and pitch & Triangular, $25[\mathrm{~mm}]$ \\
Number of tubes & 19 \\
Effective length & $1460[\mathrm{~mm}]$ \\
\hline
\end{tabular}

Boundary conditions are presented now. Desired velocity and temperature values are assigned to the bulk flow at the shell inlet. The inlet velocity profile is assumed to be uniform and the inlet temperature is set as $293 \mathrm{~K}$. Out-flow boundary is assigned to the outlet nozzle. Non-slip boundary condition is applied for all surfaces. The tube wall temperature is set as a constant of $373 \mathrm{~K}$ and the shell wall is assumed to be adiabatic, assuming the shell is perfectly insulated outside. Water is selected as the working fluid. Mesh generation is performed using the ICEM software. Due to the complex structure of the SETHE, computational domain is meshed with unstructured Tet-Hybrid grid system. In order to ensure the accuracy of numerical results, careful check for the grid independence is carried out for each model. The governing equations are solved by the commercial CFD code ANSYS FLUENT 12.1. The QUICK scheme is used to discretize the convective terms and the SIMPLE algorithm is adopted to deal with the coupling between velocity and pressure. Convergence criterions for residual monitoring are set to be $10^{-6}$ for flow field and $10^{-8}$ for the energy equation.

\section{Results and Discussions}

Model Validation. In order to validate our general CFD simulation approach, the model validation is conducted. The computational results of the conventional HESB from present study are compared 
with classical empirical equations, as shown in Fig.3 and Fig.4. The computational heat transfer coefficient is compared with the Kern equation [6] and the pressure drop is compared with Bell-Delaware [7] result. Quantitatively, the maximum deviations between numerical results and empirical equations data are less than $15 \%$.

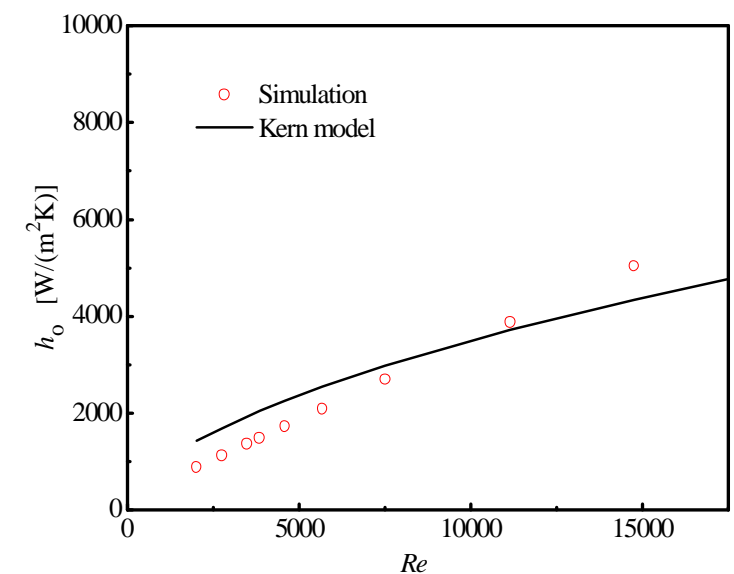

Fig.3 Comparison between the computational shell side heat transfer coefficient and the Kern equation for the HESB

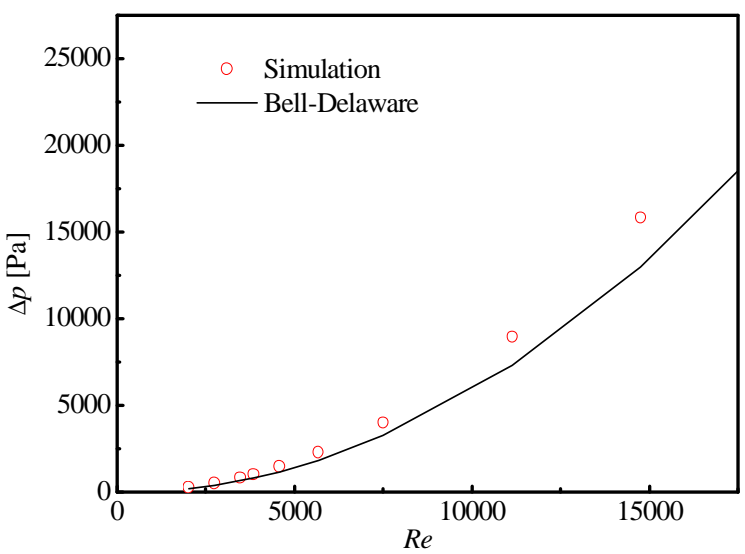

Fig.4 Comparison between the computational shell side pressure drop and the Bell-Delaware equation for the HESB

Flow Pattern, Temperature and Pressure Distributions. The flow path lines on the shell side of a SETHE are shown in Fig.5. It can be clearly observed that fluid mainly flows longitudinally along the axial direction of the tube bundle except the inlet and outlet region. However, it is not an absolutely longitudinal flow due to the special structure of the tube bundle. The spiral profiles of SETs can induce a rotary motion of fluid, which promotes the radial mixing of fluid and then results in a heat transfer augmentation to a certain degree. Fig. 6 is the two-dimensional velocity vector on the cross-section. It can be seen that the radial velocity component really exists and fluid rotation occurs in space near the shell wall.

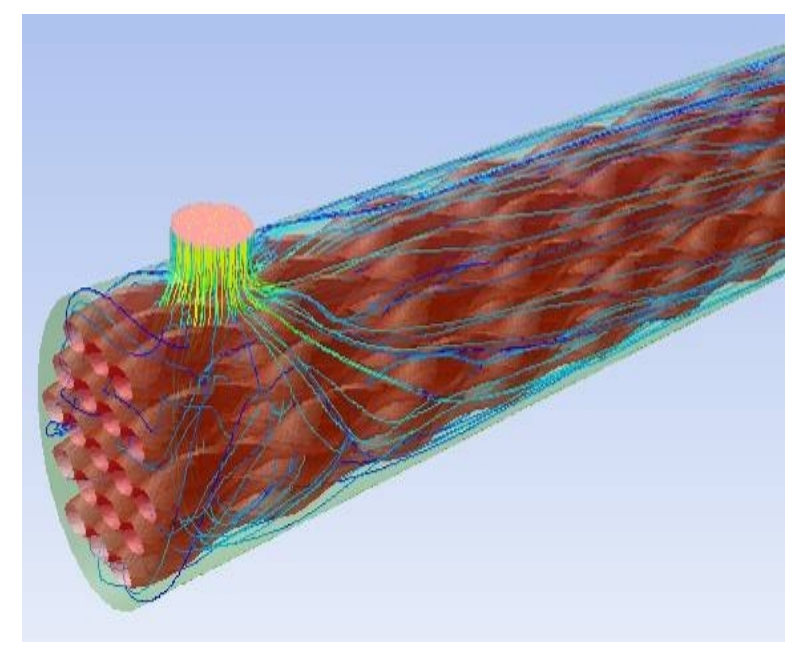

Fig.5 Path lines of fluid on shell side of the SETHE

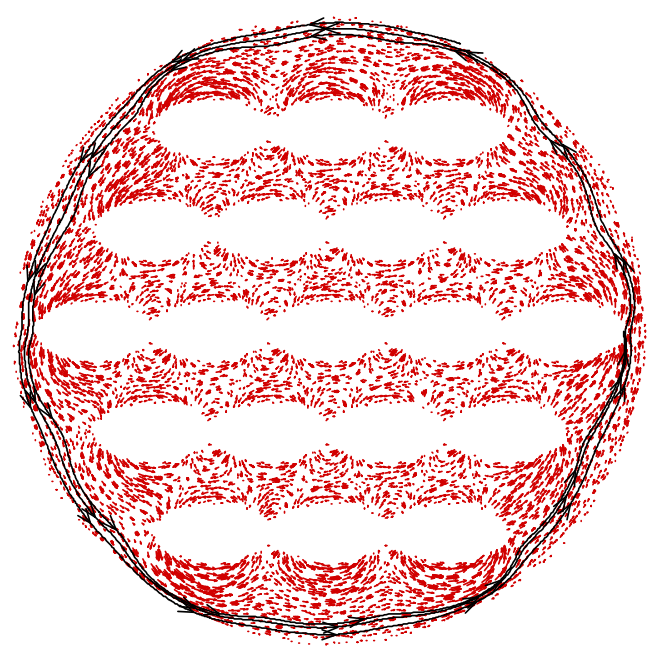

Fig.6 Two-dimensional velocity vector on the cross section of the SET bundle

Fig. 7 is the temperature cloud picture which shows the fluid temperature distribution on the cross section. It can be observed that the fluid temperature decreases gradually along the radial direction of the tube bundle from the bundle center to the shell wall. In the present simulation, heat exchange tubes are the heat source, therefore the intertube fluid can be heated to a higher temperature and 
fluid in the peripheral space that close to the inner shell wall has a relatively lower temperature. Therefore, the space between the tube bundle and the shell wall is regarded as dead zones of heat transfer. In order to overcome this, a shroud with a polygon cross section could be used to wrap the tube bundle and indeed this improvement had been applied to actual projects by the Brown Fintube Company [8].

Fig. 8 illustrates the pressure distribution on the cross section for an inlet velocity of $0.75 \mathrm{~m} / \mathrm{s}$. It is obvious that the pressure distribution on the section is relatively uniform; the difference between the maximum and the minimum pressure is around $3 \mathrm{~Pa}$. It is important to note that the relative low pressure also appears in area near the shell wall, where a short circuit flow may occur. A proper tube bundle shroud also can alleviate this problem.

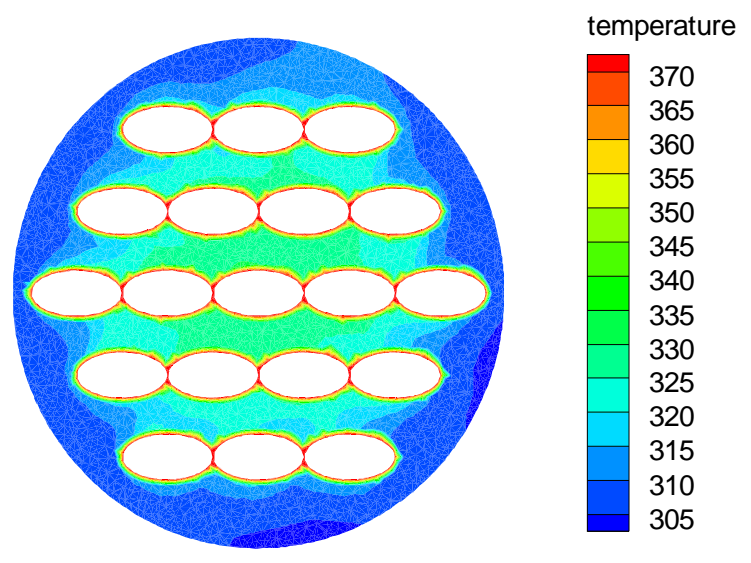

Fig.7 Temperature distribution on the cross section of the SET bundle

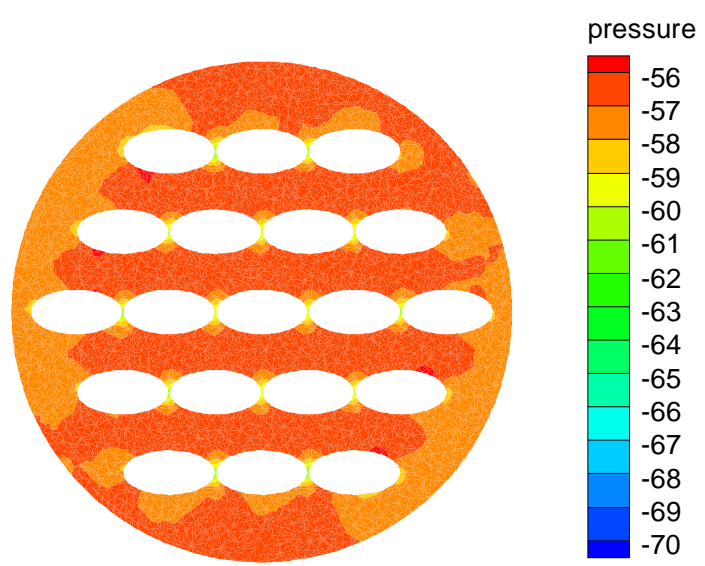

Fig. 8 Pressure distribution on the cross section of the SET bundle

Heat Transfer and Flow Resistance. Fig.9 shows the variation of shell side heat transfer coefficient with Reynolds number for the SETHE and the HESB. One can find that the shell side heat transfer coefficient of the SETHE is slightly higher than that of the SETHE when the Reynolds number is lower than 3000. However, when the Reynolds number exceeds 3000 , the heat transfer coefficient of the HESB is much higher, and maximum up to1.8 times of the SETHE. This indicates the heat transfer performance of the HESB is better than the SETHE. Fig.10 presents the comparison of shell side pressure gradients of the SETHE and the HESB. The pressure drop of the SETHE is apparently lower than the HESB. The SETHE does not possess such well heat transfer ability as the HESB, but its shell side flow resistance reduction is more evident relative to the disadvantage in heat transfer. The SETHE is around 0.6-0.7 times the shell side heat transfer coefficient of the HESB, but its shell side pressure gradient is even less than one-twelfth of the latter. Fig. 11 shows the comprehensive performance comparison between the SETHE and the HESB. The comprehensive performance is evaluated by the ratio of heat transfer coefficient to pressure drop gradient, which is a combined consideration of heat transfer and flow resistance. Clearly, the SETHE has a better comprehensive performance. The heat transfer coefficient per pressure gradient for the SETHE can be more than 10 times higher than the HESB. By comparison between the SETHE and other heat exchangers, the point that the flow pattern of fluid in shell influences the shell side heat transfer and pressure drop is notably emphasized again. Fluid in shell of the HESB flows across heat exchange tubes along a zigzag path, which improves the turbulence intensity of fluid thus to enhance heat transfer and also increases flow resistance tremendously at the same time. The mainly longitudinal flow in shell of the SETHE cannot bring about such improvement of turbulence as the transversal flow but can reduce the flow resistance to a lower level and upgrade the comprehensive performance. 


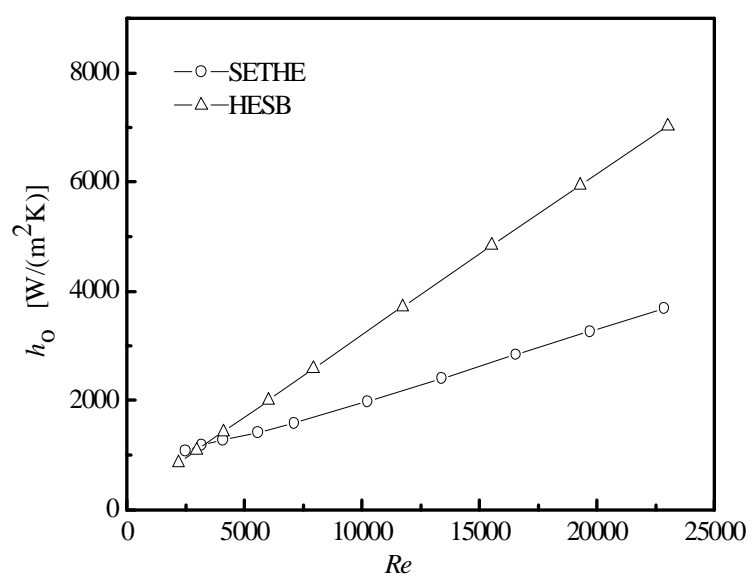

Fig.9 Shell side heat transfer coefficients for the SETHE and HESB

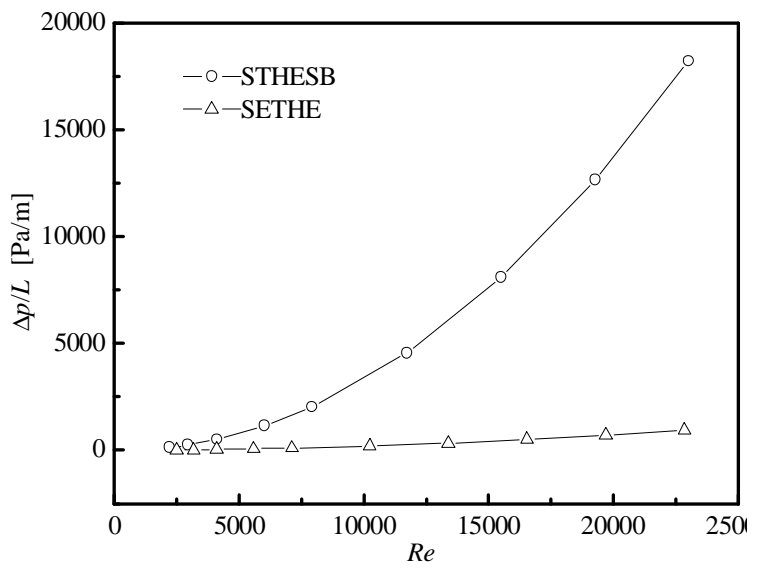

Fig.10 Shell side pressure gradients for the SETHE and HESB

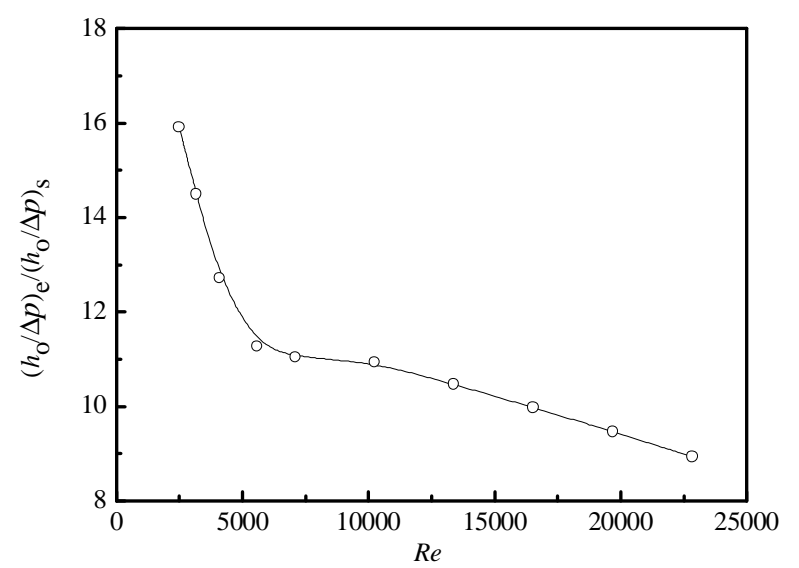

Fig.11 Ratio of heat transfer coefficient per pressure gradient

Application occasions of the SETHE. From the above analysis, it is known that the shell side heat transfer performance of the SETHE is poorer than that of the conventional HESB, but the fluid flow resistance on shell side of the SETHE is far lower than that of the HESB. Therefore, the SETHE is more suitable for the occasion that the technical process has a strict requirement on the shell side pressure drop of the heat exchanger, and can meet the high velocity operation of shell side fluid. In addition, due to the tight self support of the spiral elliptical tube bundle and the free flow of the shell side fluid, the SETHE can be used instead of the traditional tube heat exchanger for some working conditions, such as the case of the shell side fluid is easy to scale or the flow may induce the tube bundle.

\section{Conclusions}

The present study conducts shell side heat transfer and fluid flow simulation of the SETHE with a CFD method. The major findings are summarized as follows.

(1) Fluid in shell of the SETHE mainly flows longitudinally; therefore, there is no dead zone of flow on shell side. On the cross section, the distribution of velocity and pressure is more uniform, and the utilization ratio of heat exchange surface is higher than the HESB. The SETHE is suitable for many industrial conditions, especially suitable for reducing shell side pressure drop and avoiding tube bundle vibration.

(2) The shell side heat transfer coefficient of the SETHE is lower than that of the HESB, and is 0.6-0.7 times of the later. The fluid flow resistance on shell side of the SETHE is much lower than that of the HESB, and the pressure gradient of the SETHE even can be only one twelfth of the latter. Therefore, the SETHE has a better comprehensive performance than the HESB, the heat transfer 
coefficient per pressure drop can be 8-16 times of the HESB.

\section{Acknowledgments}

The authors are grateful for the support by the National Science and Technology Major Project of the Ministry of Science and Technology of China-Large-scale advanced pressurized water reactor and high temperature gas cooled reactor nuclear power plant (2015ZX06002-007).

\section{References}

[1] B. G. Srbislav, M. J. Branislav, S. Marko, Research on the shell-side thermal performances of heat exchangers with helical tube coils, Int. J. Heat Mass Tran. 55 (2012) 4295-4300.

[2] D. Butterworth, Process heat transfer 2010, App. Therm. Eng. 24 (2004)1395-1407.

[3] S. Yang, L. Zhang, H. Xu, Experimental study on convective heat transfer and flow resistance characteristics of water flow in twisted elliptical tubes, App. Therm. Eng. 31 (2011) 2981-2991.

[4] X. H. Tan, D. S. Zhu, G. Y. Zhou, L. D. Zeng, Experimental and numerical study of convective heat transfer and fluid flow in twisted oval tubes, Int. J. Heat Mass Tran. 55(17-18) (2012) 4701-4710.

[5] W. Q. Tao, Numerical Heat Transfer (In Chinese), second ed., Xi'an Jiaotong University Press, Xi'an, 2001.

[6] S.W Qian, Heat Exchanger Design Handbook (In Chinese), first ed., Chemical Industry Press, Beijing, 2002.

[7] Bell K. J. Delaware Method for Shell Side Design, Heat Exchangers-Thermal Hydraulic Fundamentals and Design, first ed., Taylor \& Francis, Washinton, D.C., 1981.

[8] Information on http://www.brownfintube.com 